\title{
Proboscis Lateralis: A Case Report of Nasal Aplasia with Complete Agenesis of Maxilary and Ethmoidal Sinuses
}

\author{
Shamim R*, Yahia FH, Wan Islah L, Raman R. \\ Department of Otorhinolaryngolgy, University Malaya, Kuala Lumpur, Malaysia.
}

\begin{abstract}
We report a child with Proboscis Lateralis with nasal aplasia and complete agenesis of maxillary and ethmoidal sinuses. This is a rare congenital malformation. Embryological basis has not been proven, and it is often associated with facial malformation. However, no such abnormality was noted in our patient. This condition is diagnosed clinically and confirmed radiologically of which CT scan plays a pivotal role. Reconstructive surgery is planned at the age of fifteen years.
\end{abstract}

KEYWORDS: Proboscis Lateralis, Nasal Aplasia with maxillary and ethmoidal agenesis, Congenital Craniofacial Anomaly.

\section{CASE}

A five-year-old child was brought to our clinic by her father. She is the fifth of six siblings, and all the other siblings are free from congenital anomaly. Her anomaly was detected at seven months of gestational period. The child was born via spontaneous vaginal delivery with birth weight of $1.95 \mathrm{~kg}$. The mother was not on any teratogenic medication throughout her pregnancy. The marriage was not consanguineous. Although there is a family history of Down's syndrome with congenital heart disease, none was recorded of similar congenital deformity.

She presented with obliterated left nasal cavity with a tube-like structure growing from her left medial canthus. Further examination reveals a dimple in the tube-like structure with ipsilateral nasal aplasia. There was no diplopia despite the slight lowering of left orbit (Fig. 1). There was also no coloboma or epiphora. Her neurological,

Corresponding Author:

Assistant Professor Dr. Shamim Rahman

Department of Otorhinolaryngolgy,

International Islamic University Malaysia, Kuala Lumpur, Malaysia.

Tel : +60126359456

E-mail:drsr79@gmail.com physical, and intellectual developments are normal for her age. She has no difficulty in swallowing as the hard and soft palate have developed without a defect. She is able to carry out her daily activity without any respiratory difficulty. This is possible because the nasal cavity is well compensated. The nasal septum is deviated towards the left side, and the right turbinates are hypertrophied. The palates are normal and the soft palate moves well with swallowing. The heminasal aplasia with ipsilateral agenesis of maxillary and ethmoidal sinus was confirmed by $\mathrm{CT}$ scan (Fig. 2). Reconstructive surgery is planned when she reaches fifteen years old.

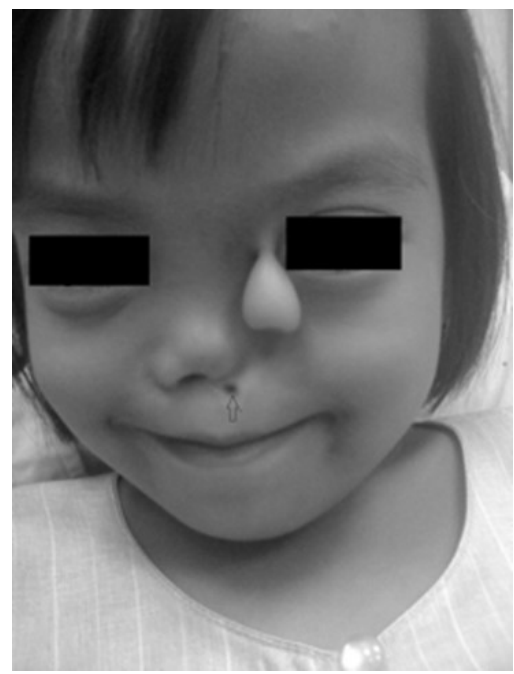

Fig. 1: A child with Proboscis Lateralis, nasal aplasia with maxillary and ethmoidal agenesis, and a prominent nasal pit. 


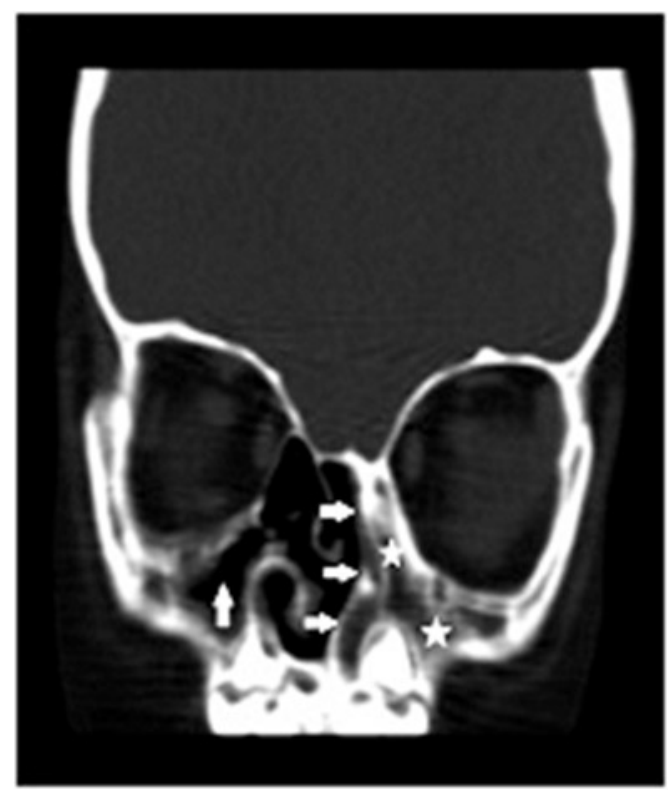

Fig. 2: Coronal CT shows a well formed right maxillary cavity with hypertrophied turbinates, deviated nasal septum, and agenesis of left nasal, maxillary, and ethmoidal sinuses (as evidenced by the absence of pneumatisation). CT scan also shows a slight lowering of left orbit.

\section{DISCUSSION}

Proboscis Lateralis is a rare congenital deformity which has a sporadic nature ${ }^{1}$. It was first described by Forester in 1861 and later by Selenkoff in 1884 who included an autopsy evidence. Several known points of embryonic fusion line are described by Thorne et $\mathrm{al}^{2}$ :

Level 1: between the anterior maxillary process and the frontonasal process

Level 2: supramedial canthal area

Level 3: medial canthal area

Level 4: inframedial canthal area

Level 5: supranostril area

Various classifications of Proboscis Lateralis are mentioned in the English literature ${ }^{3}$. Boo-Chai ${ }^{4}$, who particularly showed a male preponderance with no side preference, classified the condition into four: Group 1: Proboscis with normal nose and all other associated anomaly (rarest form)

Group 2: Proboscis with only nasal deformity

Group 3: Proboscis with nasal deformity and associated with a deformity of the eye, and/or its adnexa on the same side

Group 4: Proboscis with defects in group 3, but is also associated with cleft lip and/or palate

Another theory suggests that an imperfect fusion of the lateral nasal wall and maxillary processes leads to Proboscis Lateralis ${ }^{5}$. In another study, Proboscis Lateralis was attested to be the result of fusion of maxillary process of the affected site with the globular and nasal process of the opposite site ${ }^{6}$. Thus according to Boo-Chai's classification our patient falls under group 2. Similar condition has been reported by Udyan $\mathrm{H}$. Vyas et al. ${ }^{7}$ but in their case Proboscis Lateralis with hypoplastic ipisilateral nasal and sinus cavity were presented. In our case, we present a patient with a complete aplasia of ipsilateral nose and agenesis of maxillary and ethmoidal sinuses. For this patient we have commenced early management to prevent psychosocial consequence related to this deformity. Complete aesthetic treatment, however, has been delayed to make way for complete growth of nasal skeleton. We plan to use a paramedian flap with aid of costal cartilage as a framework to reconstruct the nose $^{8,9}$. We opine that the nasal passage, however, needs no reconstruction because the nasal passage is patent as seen on CT scan (Fig. 2).

\section{Embryology}

At around the fourth week, the development of brachial apparatus and primitive gut makes its appearance. It is around this period where the embryo gets its appearance of head and face with an identifiable orifice in the middle known as the stomodeum. The stomodeum would be surrounded by a few prominence; namely frontonasal prominence superiorly, two maxillary prominence laterally, and two mandibular prominence inferiorly. The neural crest cells that settle to form the frontonasal mass first migrates from the Prosencephalic region (Forebrain) and are later joined by other migrating cells. The maxillary and mandibular prominence is derived from the first pharyngeal pouch. The frontonasal prominence surrounds the ventrolateral part of the forebrain and gives rise to optic vesicles, which in turn forms the eyes. The frontal portion of frontonasal prominence forms the forehead. The nasal part of frontonasal prominence subsequently differentiates into nasal placodes.

Rapid proliferation of the underlying mesenchyme produces a horseshoe shaped ridge which converts the nasal placode into nasal pit, bounded laterally by lateral nasal placode, and medially by medial nasal placode ${ }^{10}$. The medial nasal placodes of both sides together with frontonasal process gives rise to middle portion of nose, middle portion of upper lip, anterior portion of the maxilla, and the primary 
palate. The lateral nasal placode on both sides forms the alae. The maxillary process grows medially and approaches the lateral nasal placodes, and it is separated by a deep groove. This groove eventually becomes the nasolacrimal duct ${ }^{10}$. In Proboscis Lateralis, the primary insult should involve nasal placode or forebrain at or before the fifth week of gestation ${ }^{11}$.

In our patient, the formation of left nasal cavity and sinuses has been arrested at this stage but she incurred no insult to her forebrain, with ipsilateral eye, nasolacrimal duct, and mandible intact. The palate and the nasal septum were also intact, and the contra lateral nasal cavity and paranasal sinuses were well formed.

\section{REFERENCES}

1. Abou-Elhamd KE. Proboscis lateralis: a report of two cases. Int J Pediatr Otorhinolaryngol 2004; 68: 503-5.

2. Thorne MC, Ruiz RE, Carvalho J, Lesperance $M M$. Proboscis lateralis: case report and review. Arch Otolaryngol Head Neck Surg 2007; 133:1051-3.

3. Sakamoto Y, Miyamoto J, Nakajima H, Kishi K. New classification scheme of proboscis lateralis based on a review of 50 cases. Cleft Palate Craniofac J 2012; 49:201-7.

4. Boo-Chai K. The Proboscis Lateralis-A 14-Year Follow-Up. Plast Reconstr Surg 1985; 75:56977.

5. Coessens B, De Mey A, Lejour M. Correction of supernumerary nostrils. Int J Pediatr Otorhinolaryngol 1992; 23:275-80.

6. Brown K, Brown OE. Congenital malformations of the nose. Otolaryngology Head and Neck Surg 1998; 3.

7. Vyas UH, Raibagkar SC, Vora HJ, Bhavsar D. Proboscis lateralis-A 17 years follow-up, a case report. Indian J Plast Surg 2003; 36:39.

8. Fischer H, Eppstein RJ, von Gregory HF, Gubisch W. Nasal reconstruction in heminasal deficiency (proboscis lateralis): two case reports, with airway reconstruction in one case. Facial Plast Surg. 2014 Jun; 30(03):36570.

9. Chauhan DS, Guruprasad Y. Proboscis lateralis. J Oral Maxillofac Surg 2010; 9:162-5.

10. Rontal M, Duritz G. Proboscis lateralis: case report and embryologic analysis. The
Laryngoscope 1977; 87:996-1006.

11. Cate-Ten AR. Oral histology: development, structure, and function. 1998: pg 26-39. 
